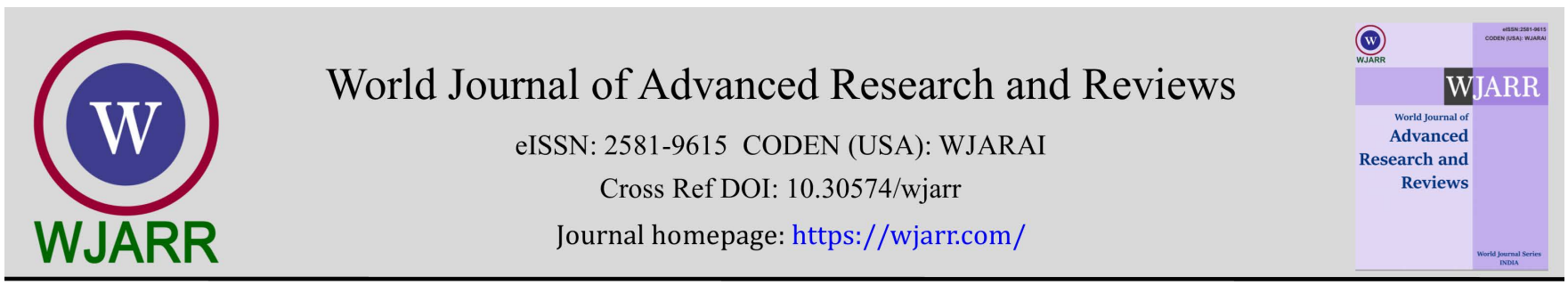

(RESEARCH ARTICLE)

\title{
A comparative assessment of GSM and UMTS Networks
}

\author{
Ukoette Jeremiah Ekah ${ }^{1, *}$ and Chibuzo Emeruwa ${ }^{2}$ \\ ${ }^{1}$ Department of Physics, Cross River University of Technology, Calabar, Cross River State, Nigeria. \\ 2 Department of Physics, Federal University Otuoke, Bayelsa State, Nigeria.
}

World Journal of Advanced Research and Reviews, 2022, 13(01), 187-196

Publication history: Received on 04 December 2021; revised on 05 January 2022; accepted on 07 January 2022

Article DOI: https://doi.org/10.30574/wjarr.2022.13.1.0011

\begin{abstract}
It is common knowledge that the transition of mobile networks from one generation to another is basically for the improvement in the network's Quality of Service (QoS). Bearing this in mind, we will assumme that the Universal Mobile Telecommunication System (UMTS) will outperform the Global System for Mobile Communication (GSM), hence, the motivation to conduct this study in Calabar, Nigeria, for four mobile networks; MTN, Airtel, Globacom and 9mobile. With the aid of a TEMS investigation software installed in a laptop, a measurement campaign was carried out and log files collected, with focus on Call Setup Success Rate (CSSR), Dropped Call Rate (DCR), Handover Success Rate (HOSR), Call Setup Time (CST), network coverage and network quality. The collected data was analyzed with the aid of a TEMS discovery software. The analyzed data for each Key Performance Indicator (KPI) was compared with the minimum benchmark of the telecommunications regulatory body, the Nigerian Communication Commission (NCC). Result reveal that there was no outright improvement in the QoS and there was fluctuation in the QoS provided by the network operators. We therefore conclude that the network operators, either did not make accurate planning before installing their base stations or do not optimize their networks frequently and this led to poor QoS in most cases.
\end{abstract}

Keywords: Call Setup Success Rate; Dropped Call Rate; Call Setup Time; Handover Success Rate; Network coverage; Network quality

\section{Introduction}

These days, mobiles rule our lives, but then, it has simplified communication. The massive transformation of the mobile industry over the past few years has become more pervasive than anyone could have imagined when the cellular concept was first deployed [1] [2]. Our diversity in culture has played a crucial role in this tremendous growth, as they adopted mobile technology in a friendly manner [2]. Consumers are demanding more advanced and useful applications and this has demonstrated conclusively that wireless communication is not just robust, but a viable voice and data transport mechanism [3]. The astounding development of mobile industry is the outcome of modernized fundamentals in mobile networks paradigm.

Wireless communication has some special characteristics that have motivated specialized studies. First, it relies on a scarce resource - namely, radio spectrum state. Second, the use of spectrum requires the development of key complementary technologies that allow higher frequencies to be utilized more efficiently. Finally, because of its special nature, the sufficient use of spectrum requires the coordinated development of standards [1]. Each generation has some standards, capacities, techniques and new features which differentiates it from previous generations. Due to these new features, the number of mobile phone subscribers increases daily. Hence, there is need for capacity improvements in wireless communications [4].

\footnotetext{
* Corresponding author: Ukoette Jeremiah Ekah

Department of Physics, Cross River University of Technology, Calabar, Cross River State, Nigeria.

Copyright (C) 2022 Author(s) retain the copyright of this article. This article is published under the terms of the Creative Commons Attribution Liscense 4.0.
} 
The UMTS technology is the third generation of mobile phone standards and the technology that supersedes the GSM and precedes the Long Term Evolution (LTE) [5]. The GSM technology uses digitally modulated Time Division Multiple Access (TDMA) and Code Division Multiple Access (CDMA). Services provided are text messages and voice calls which are secured since they are digitally encrypted [6]. The UMTS technology uses CDMA, EDGE, Broadband, Wireless Fidelity (WI-FI), Wireless broadband (Wi-Bro) and Interactive Voice Response Service (IVRS). This technology enable operators offer a wider range of services with greater network capacity through improved spectral efficiency. Enhanced voice and video calls, broadband wireless data, mobile TV, GPS, video conferencing, WEB and WAP browsing at higher speeds are enabled [7].

The two technologies described above are used in Nigeria for voice services and due to the rapid increase in the number of subscribers, there is a need for frequent monitoring of the networks which is needful for appropriate regulations, quality assurance [8] and optimization. Several researchers have investigated network performance in various locations in Nigeria and this not limited to researches conducted by [9][10][11][12]. The results of the conducted research depict poor performance by the operators which has further motivated the essence of this research.

This article renders the comparative study of GSM and UMTS QoS in Calabar, Nigeria, with the aim of assessing through a drive test, which of the network technologies perform better, based on their KPIs. It is worthy to note that the KPIs under investigation are Call Setup Time (CST), Call Setup Success Rate (CSSR), Drop Call Rate (DCR), Handover Success Rate (HOSR), network coverage and network quality, which shall be adjudged based on the performance threshold stipulated by the telecommunication regulatory body in Nigeria, the NCC. The result of this study will keep the network operators updated, so that they visit their base stations for optimization.

\section{Material and methods}

In the course of this study, a TEMS 15.1 investigation software was installed in a laptop. Connected to the laptop are four TEMS phones in which four SIM cards are inserted into it. Each of the SIM cards represent the networks (MTN network, Globacom network, Airtel network and 9mobile network) under investigation. A Garmin Global Positioning System (GPS) was used for position location during the drive test. USB hub, a car inverter and a car are the materials used for this study in Calabar, Nigeria. The GPS and the TEMS phones are powered by a USB hub connected to the laptop.

An extensive drive test measurement is conducted and the KPIs (CSSR, DCR, CST, HOSR, and network quality and network coverage) under investigation are collected over GSM and UMTS base stations along the same route. Collected log files are analyzed using a TEMS discovery software and the results are presented in the form of tables and plots. The results are further analyzed based on the NCC performance threshold so as to deduce which network technology performs better.

\section{Results and discussion}

The comparative assessment of GSM and UMTS technology based on KPI data obtained and analyzed has been established. Obtained results are compared with the NCC minimum benchmark. The minimum benchmark is listed as follows: CSSR $\geq 98 \%$, DCR $\leq 1 \%$, CST $\leq 6$ secs, HOSR $\geq 98 \%$. Network coverage $\geq-85 \mathrm{dBm}$, network quality $\geq-9 \mathrm{dBm}$ for UMTS technology and $\geq-4 \mathrm{dBm}$ for GSM technology [13]. The established results are rendered in five stages. We shall first appraise GSM and UMTS technology for MTN network, followed by Airtel network, Globacom network, 9mobile network and then make an all-inclusive assessment of the four networks under study.

\subsection{Analysis of GSM and UMTS Technology for MTN Network}

Table 1 gives a picture of four KPIs for MTN network. In comparing the results, we could picture that the time to connect a call in the UMTS technology is faster than in the GSM technology. Moreover, in the UMTS technology, there was a complete and successful handover and no call was dropped. This is an expression of excellent service retainability. In the GSM technology, there were dropped calls and in a value that is not within the NCC benchmark. This was also observed in the rate of dropped calls which was lower than the performance threshold. For CSSR, the GSM technology performed better. However, both technology met with the minimum benchmark, therefore, we conclude that both technology has good service accessibility.

Figure 1 and 2 describes the coverage of both technologies and this is done by investigating the Received Signal Level (RxLev) for GSM and the Received Signal Code Power (RSCP) for UMTS technology. Using the benchmark of NCC, we conclude that the GSM technology had a better coverage than UMTS technology, as $96.49 \%$ of RxLev were within the NCC benchmark, compared to $92.1 \%$ of the RSCP in the UMTS technology. 
The Received Signal Quality (RxQual) and Signal-to-Interference Ratio (Eo/Io) describes the network quality for GSM and UMTS technology, as described in Figure 3 and 4 respectively. Again, the GSM technology had a better network quality than the UMTS technology. In fact, the Eo/Io value obtained for UMTS network, shows that the network requires immediate optimization.

Table 1 Summary of CSSR, DCR, HOSR, and CST Data for MTN Network

\begin{tabular}{|l|l|l|c|c|}
\hline S/N & KPI & Unit & GSM & UMTS \\
\hline 1. & DCR & $\%$ & 1.47 & 0 \\
\hline 2. & BCR & $\%$ & 0 & 1.49 \\
\hline 3. & HOSR & $\%$ & 97.13 & 100 \\
\hline 4. & CSSR & $\%$ & 100 & 98.51 \\
\hline 5. & CST & s & 2.901 & 2.211 \\
\hline 6. & Call Attempt & counts & 340 & 335 \\
\hline 7. & Handover Attempts & counts & 522 & 1788 \\
\hline 8. & Handover Failure & counts & 15 & 0 \\
\hline 9. & Blocked Calls & counts & 0 & 5 \\
\hline 10. & Calls Established & counts & 340 & 330 \\
\hline
\end{tabular}

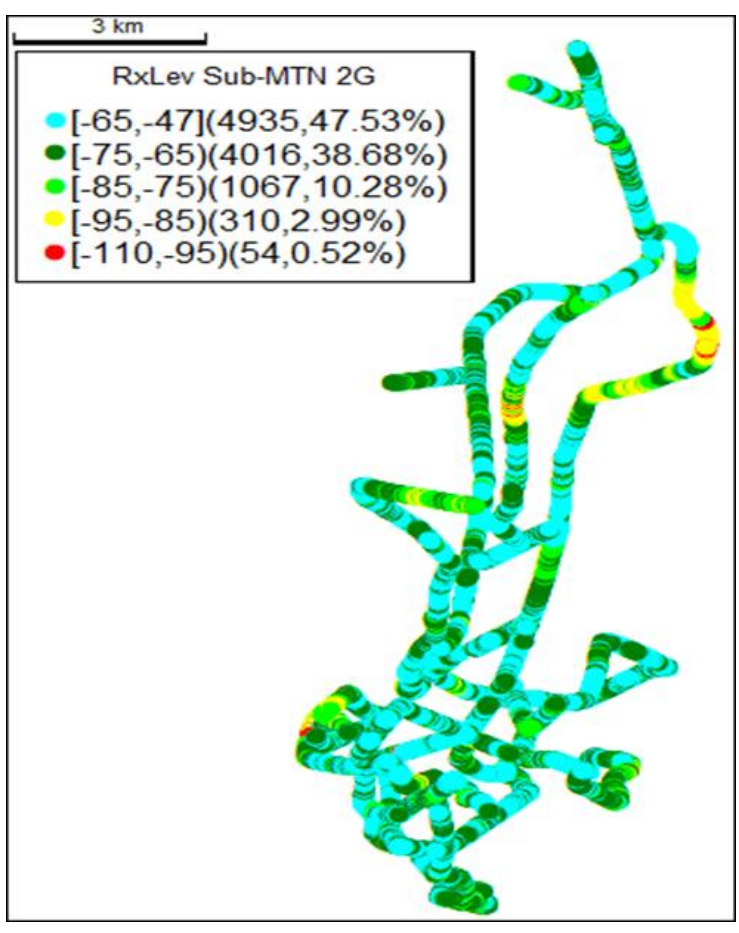

Figure 1 GSM coverage plot for MTN Network

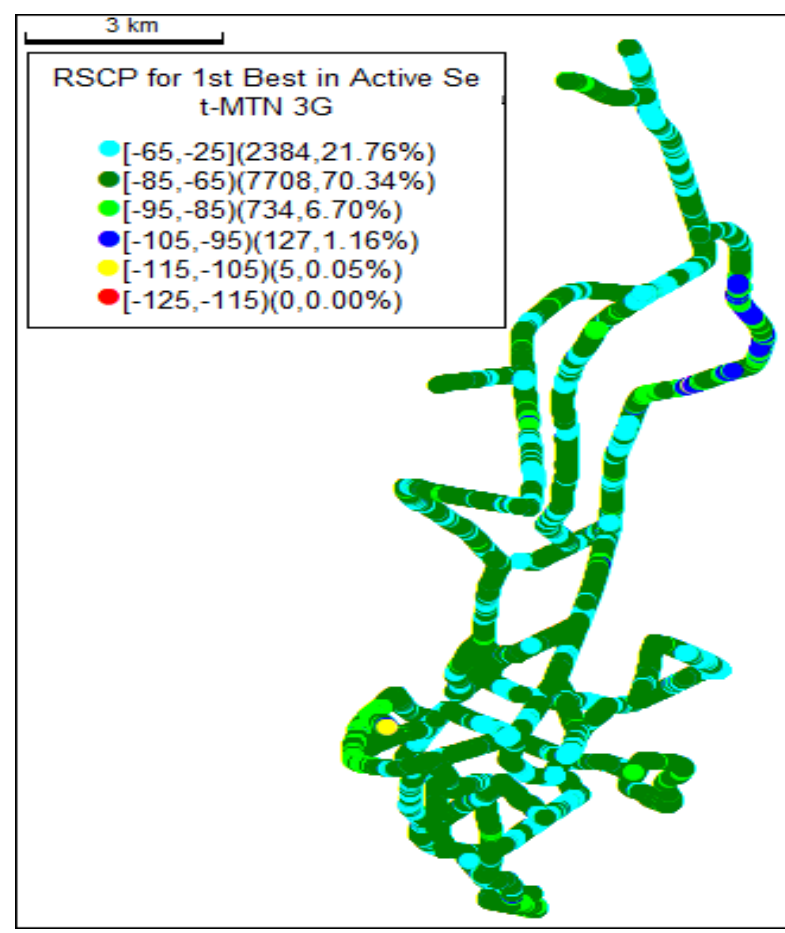

Figure 2 UMTS coverage plot for MTN Network 


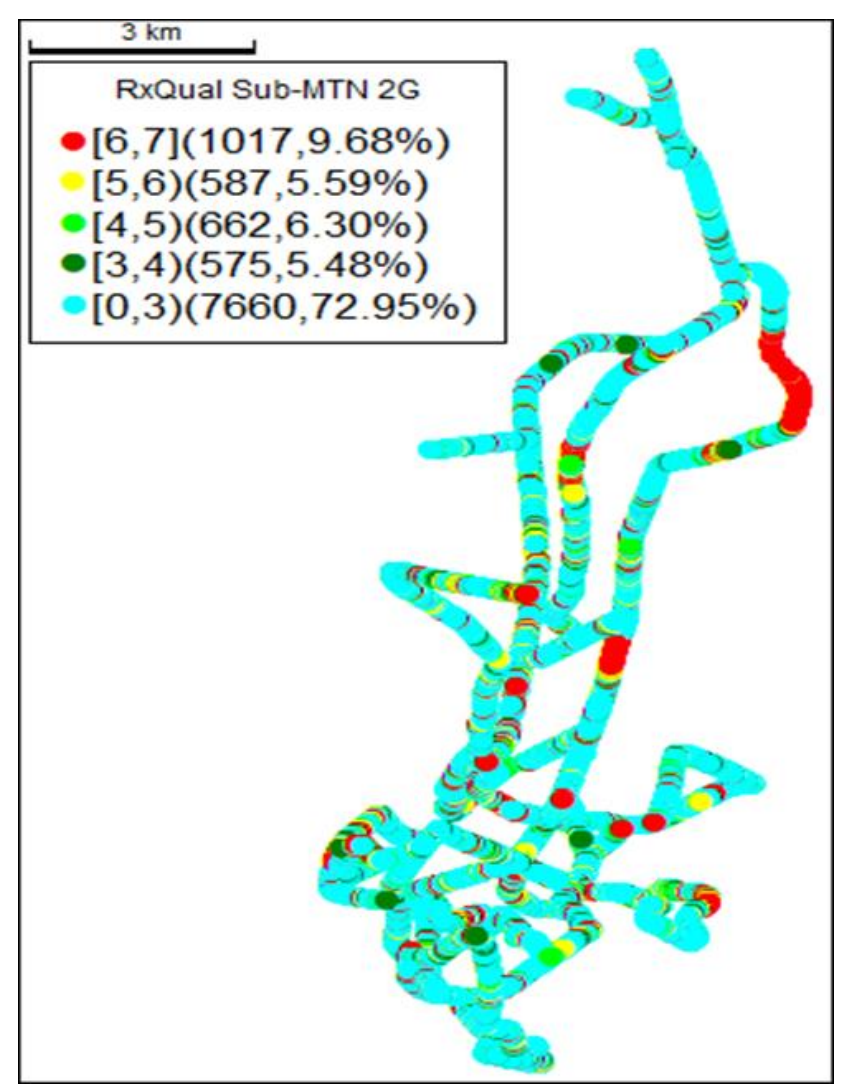

Figure 3 GSM Quality Plot for MTN Network

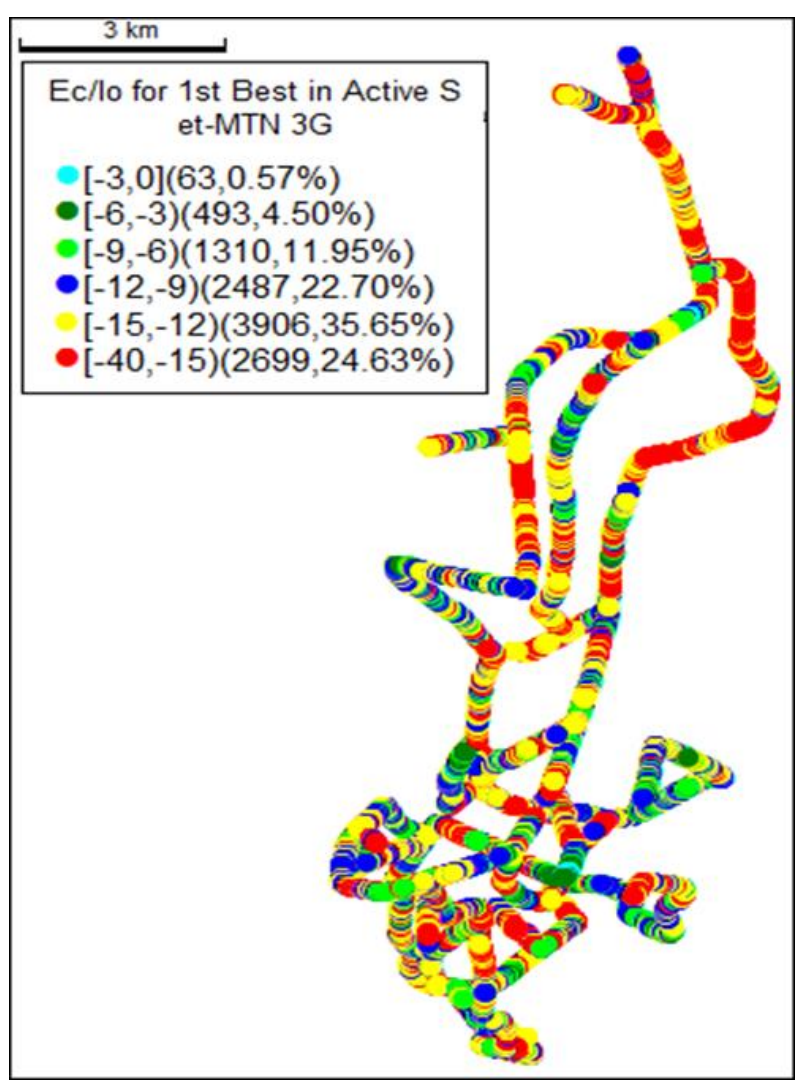

Figure 4 UMTS Quality Plot for MTN Network

\subsection{Analysis of GSM and UMTS Technology for Airtel Network}

Table 2 Summary of CSSR, DCR, HOSR, CST Data for Airtel Network

\begin{tabular}{|l|l|l|c|c|}
\hline S/N & KPI & Unit & GSM & UMTS \\
\hline 1. & DCR & $\%$ & 1.52 & 0 \\
\hline 2. & BCR & $\%$ & 0 & 0 \\
\hline 3. & HOSR & $\%$ & 99.53 & 100 \\
\hline 4. & CSSR & $\%$ & 100 & 100 \\
\hline 5. & CST & s & 3.442 & 2.854 \\
\hline 6. & Call Attempt & counts & 330 & 220 \\
\hline 7. & Handover Attempts & counts & 429 & 1937 \\
\hline 8. & Handover Failure & counts & 2 & 0 \\
\hline 9. & Blocked Calls & counts & 0 & 0 \\
\hline 10. & Calls Established & counts & 330 & 220 \\
\hline
\end{tabular}

In Table 2, we can deduce that UMTS technology of Airtel network peformed excellently in terms of service accessibility (CSSR), Service retainability (DCR and HOSR) and CST. There were no dropped calls, no handover failure and no blocked calls. For the GSM technology, there was an excellent call setup, handover and CST. However, the rate of dropped calls were below the NCC benchmark. This shows that some subscribers did not successfully complete their calls. 
For network coverage, both networks were superb. The UMTS technology had $96.36 \%$ of its RSCP within the NCC benchmark while the GSM technology had $93.64 \%$ of its RxLev within the minimum threshold level. This can be depicted in the GSM coverage plot in Figure 5 and the UMTS coverage plot in figure 6. This outstanding GSM performance continued in terms of network quality, with $90.68 \%$ of its RxQual value falling within the NCC benchmark. The reverse was the case for Airtel UMTS technology, as only $59.64 \%$ of its Eo/Io value were within the NCC benchmark. The GSM RxQual is described in the quality plot in Figure 7 while the Eo/Io value is described in the quality plot in figure 8.

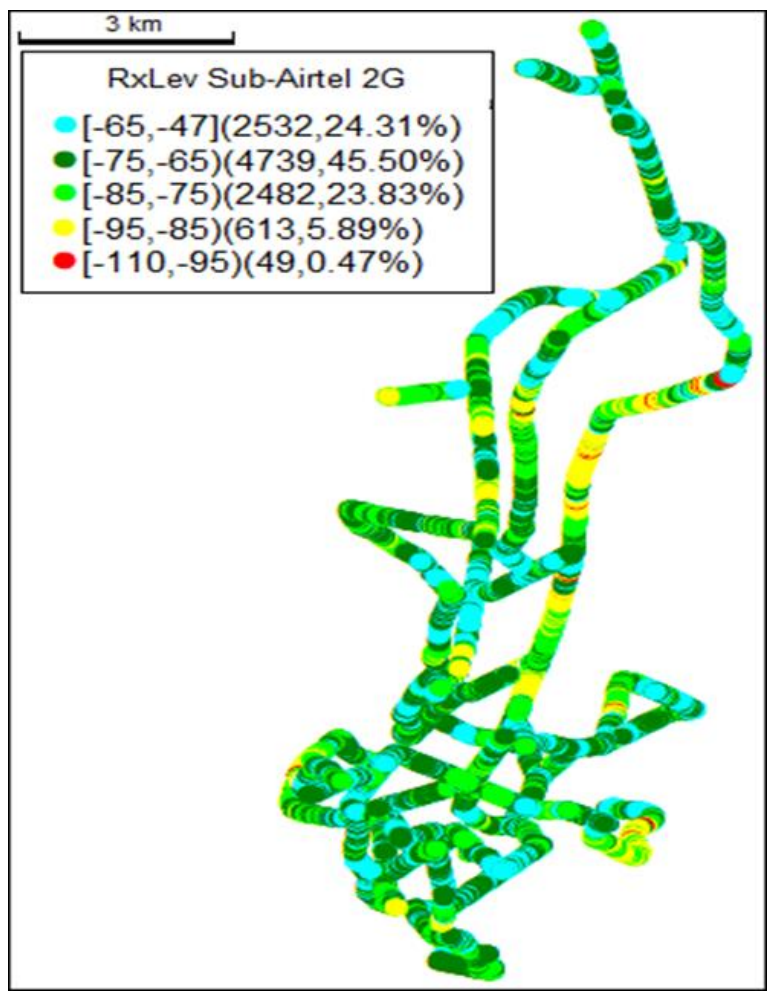

Figure 5 GSM coverage plot for Airtel Network

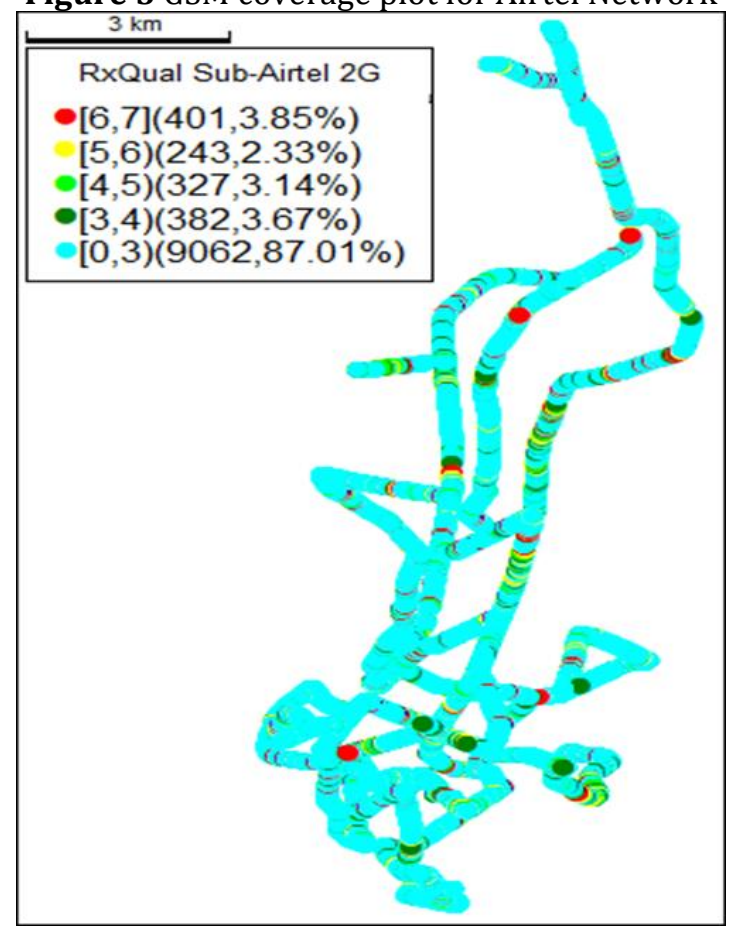

Figure 7 GSM Quality Plot for Airtel Network

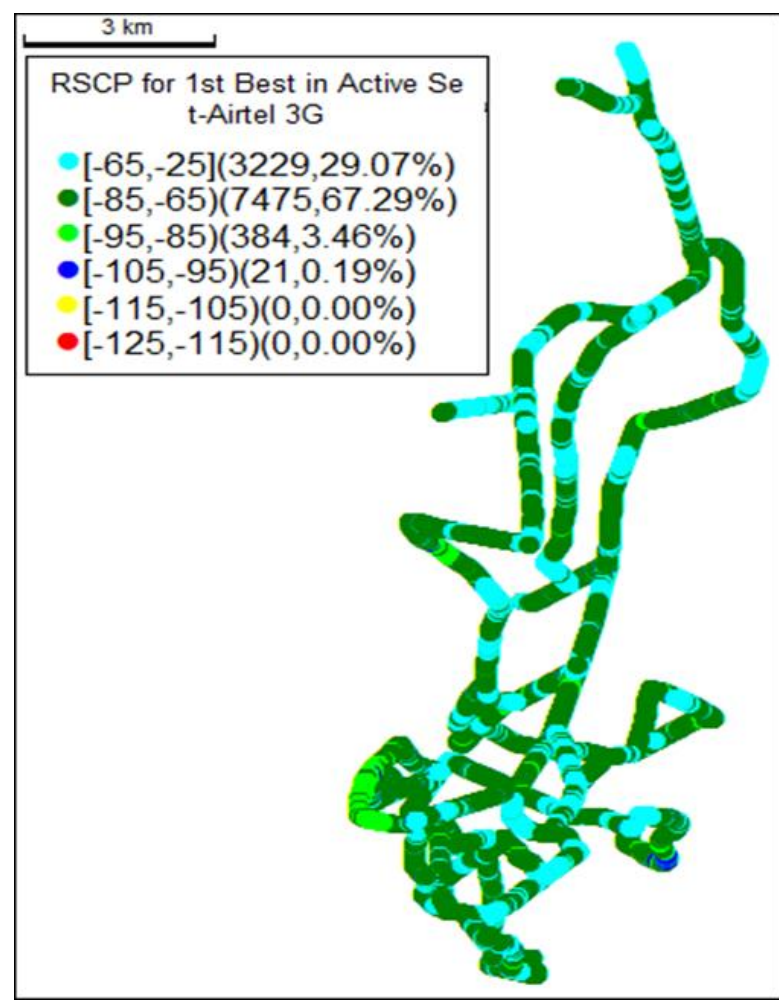

Figure 6 UMTS coverage plot for Airtel Network

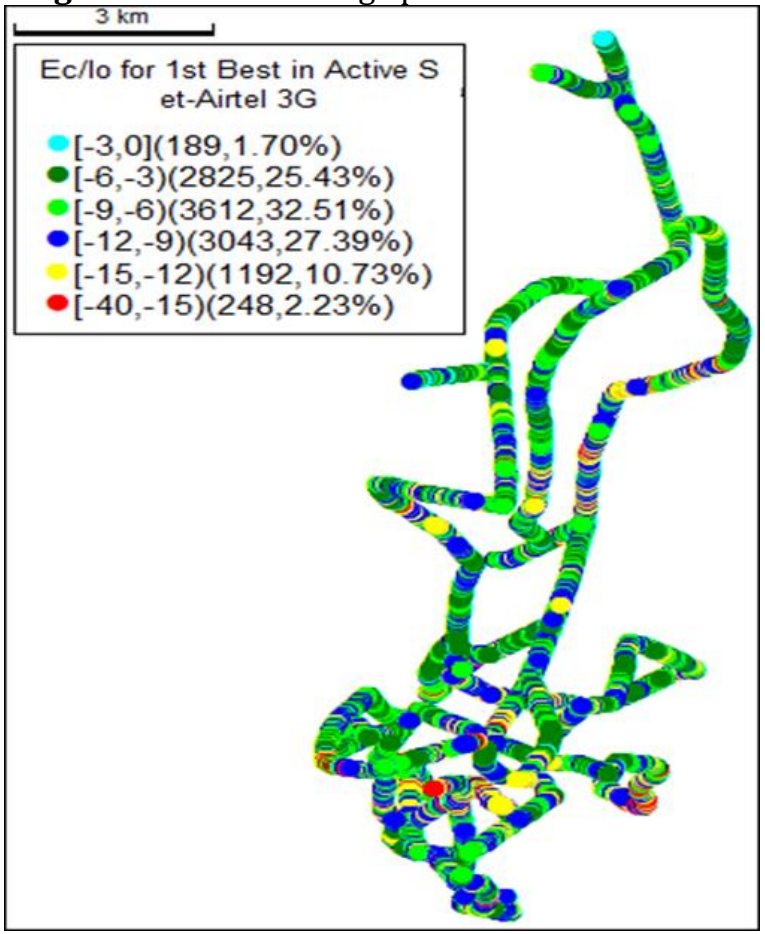

Figure 8 UMTS Quality Plot for Airtel Network 


\subsection{Analysis of GSM and UMTS Technology for Globacom Network}

Table 3 Summary of CSSR, DCR, HOSR, CST Data for Globacom Network

\begin{tabular}{|l|l|l|c|c|}
\hline S/N & KPI & Unit & GSM & UMTS \\
\hline 1. & DCR & $\%$ & 0 & 5 \\
\hline 2. & BCR & $\%$ & 0 & 1.64 \\
\hline 3. & HOSR & $\%$ & 99.54 & 99.87 \\
\hline 4. & CSSR & $\%$ & 100 & 98.36 \\
\hline 5. & CST & s & 3.259 & 3.990 \\
\hline 6. & Call Attempt & counts & 315 & 305 \\
\hline 7. & Handover Attempts & counts & 434 & 1586 \\
\hline 8. & Handover Failure & counts & 2 & 2 \\
\hline 9. & Blocked Calls & counts & 0 & 5 \\
\hline 10. & Calls Established & counts & 315 & 300 \\
\hline
\end{tabular}

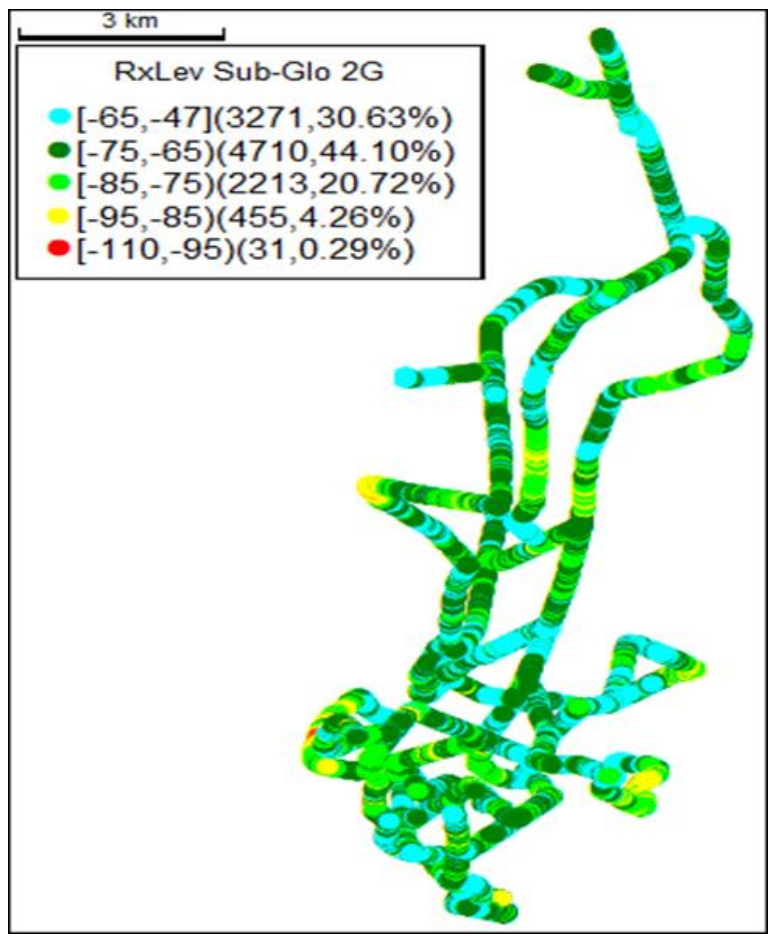

Figure 9 GSM coverage plot for Globacom Network

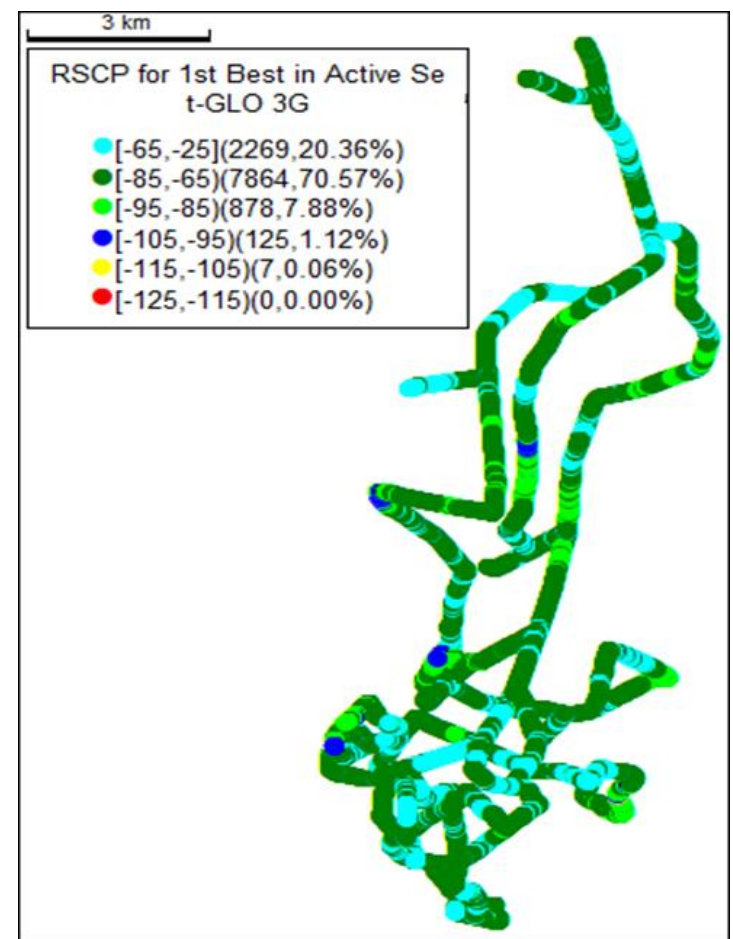

Figure 10 UMTS coverage plot for Globacom Network

Table 3 describes CSSR, DCR, HOSR and CST for Globacom network. For the four networks under investigation, Globacom happens to be the first network whose GSM technology had a faster CST than the UMTS technology, though both were within the NCC benchmark. Also, the GSM technology had an outstanding DCR, HOSR, and CSSR performance. The UMTS technology displayed excellent services in terms of HOSR and CSSR but failed in its DCR.

Figure 9 and 10 explains the network coverage of GSM and UMTS technologies for Globacom network while Figure 11 and 12 gives a picture of the network quality for GSM and UMTS technologies, respectively. From data available, the GSM technology had better coverage than the UMTS technology, though both technologies had good coverage. Furthermore, the GSM technology had a good network quality than the UMTS technology. In fact, the UMTS displayed a terrible network quality, as only $31.42 \%$ of its Eo/Io were within the NCC benchmark. 


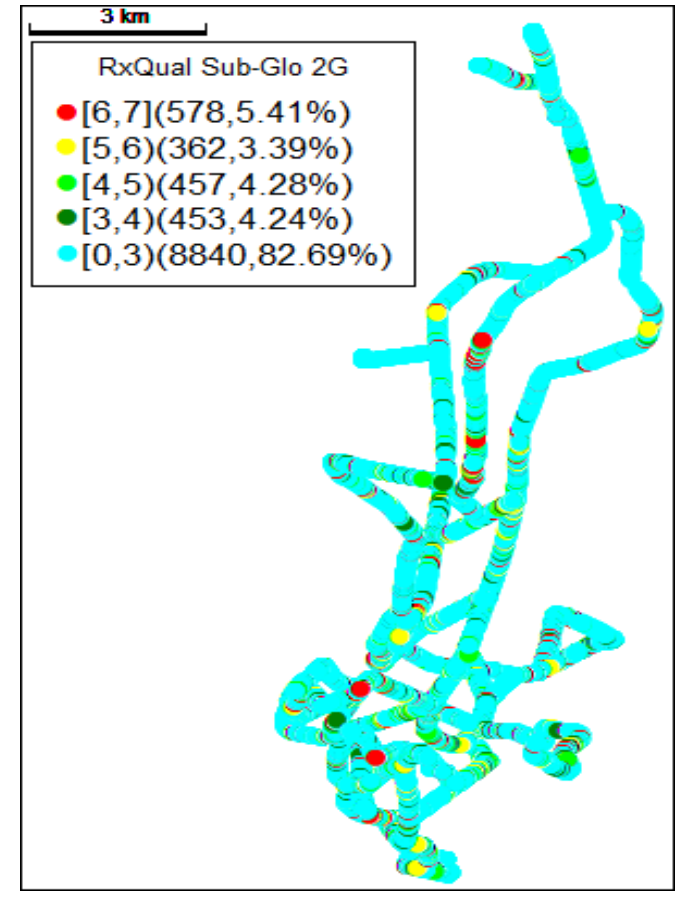

Figure 11 GSM Quality Plot for Globacom Network

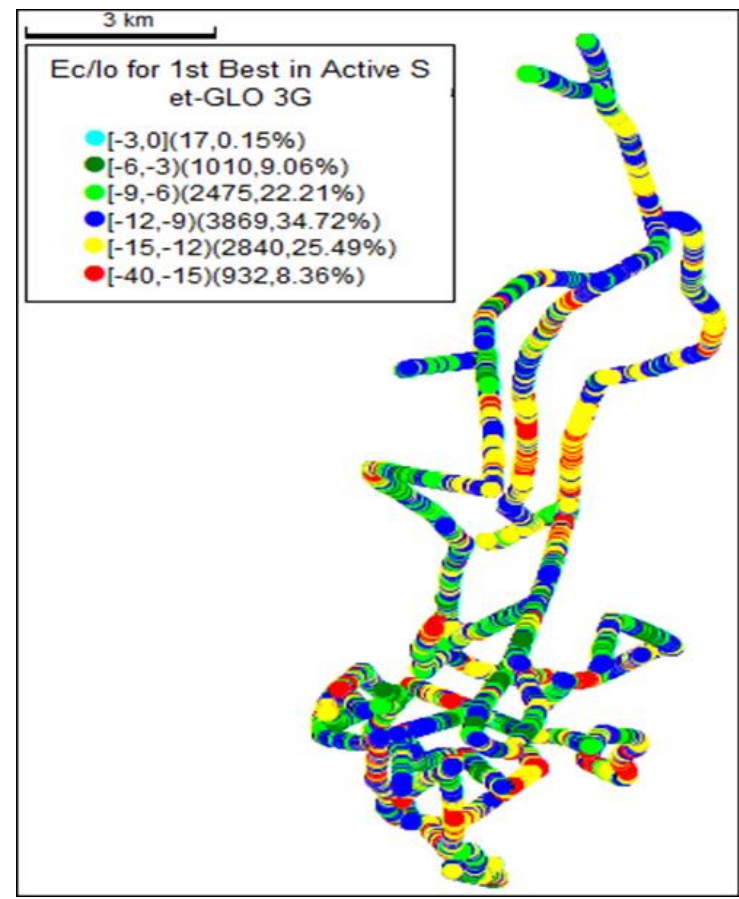

Figure 12 UMTS Quality Plot for Globacom Network

\subsection{Analysis of GSM and UMTS Technology for 9 mobile Network}

Table 4 Summary of CSSR, DCR, HOSR, CST Data for 9mobile Network

\begin{tabular}{|l|l|l|c|c|}
\hline S/N & KPI & Unit & GSM & UMTS \\
\hline 1. & DCR & $\%$ & 3.03 & 0 \\
\hline 2. & BCR & $\%$ & 8.33 & 3.23 \\
\hline 3. & HOSR & $\%$ & 98.64 & 100 \\
\hline 4. & CSSR & $\%$ & 91.67 & 96.77 \\
\hline 5. & CST & s & 3.782 & 3.324 \\
\hline 6. & Call Attempt & counts & 360 & 310 \\
\hline 7. & Handover Attempts & counts & 221 & 1598 \\
\hline 8. & Handover Failure & counts & 3 & 0 \\
\hline 9. & Blocked Calls & counts & 30 & 10 \\
\hline 10. & Calls Established & counts & 330 & 300 \\
\hline
\end{tabular}

The DCR, CSSR, HOSR and CST data for 9mobile network is summarized in Table 4. Both technologies met the benchmark for HOSR and CST but the UMTS had a better service in this aspect. For DCR, the UMTS technology experienced no dropped calls but the GSM technology performed below the NCC minimum benchmark. For CSSR, the UMTS technology performed better than the GSM technology, however, both technologies did not meet with the minimum benchmark of NCC.

Figure 13 and 14 describes the GSM and UMTS network coverage of 9mobile respectively. The RxLev of the GSM technology was better than the RSCP of the UMTS technology but both technologies displayed good coverage. Figure 15 and 16 describes the network quality of the GSM and UMTS technology for 9mobile. The GSM technology had a good network quality than the UMTS technology. An analysis of the collected data depicts than only $50.45 \%$ of Eo/Io signals of the UMTS technology fell within the NCC benchmark. 


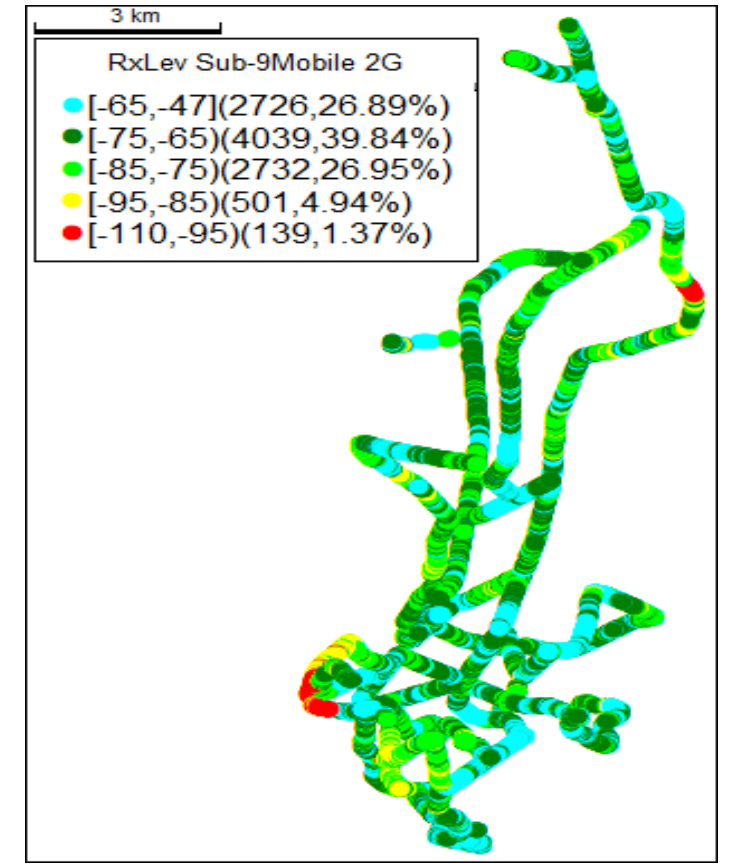

Figure 13 GSM coverage plot for 9mobile Network

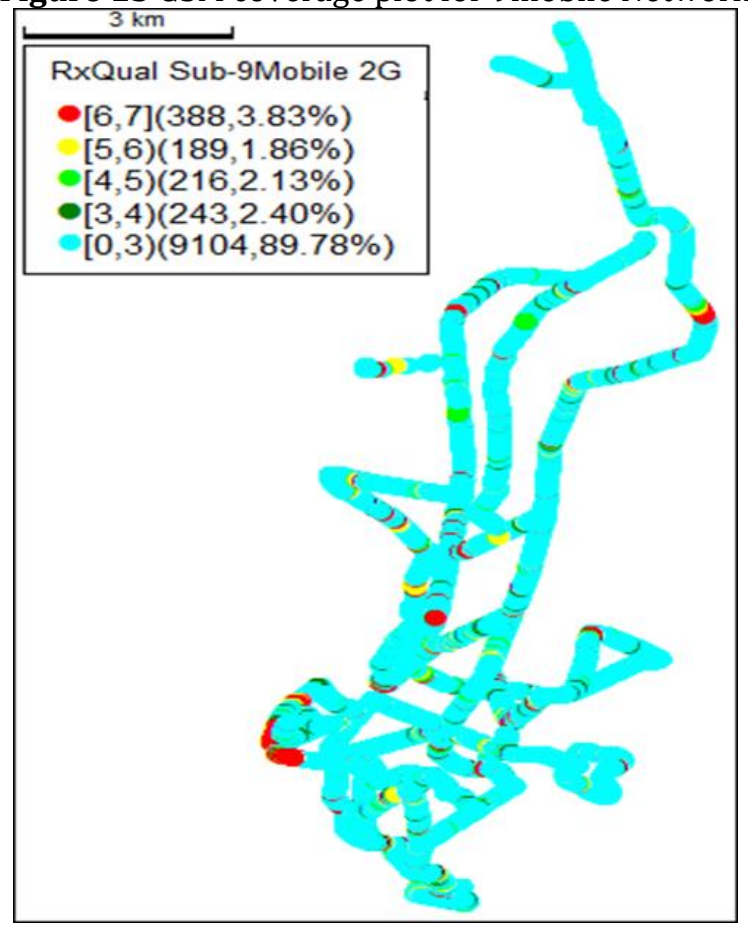

Figure 15 GSM Quality Plot for 9mobile Network

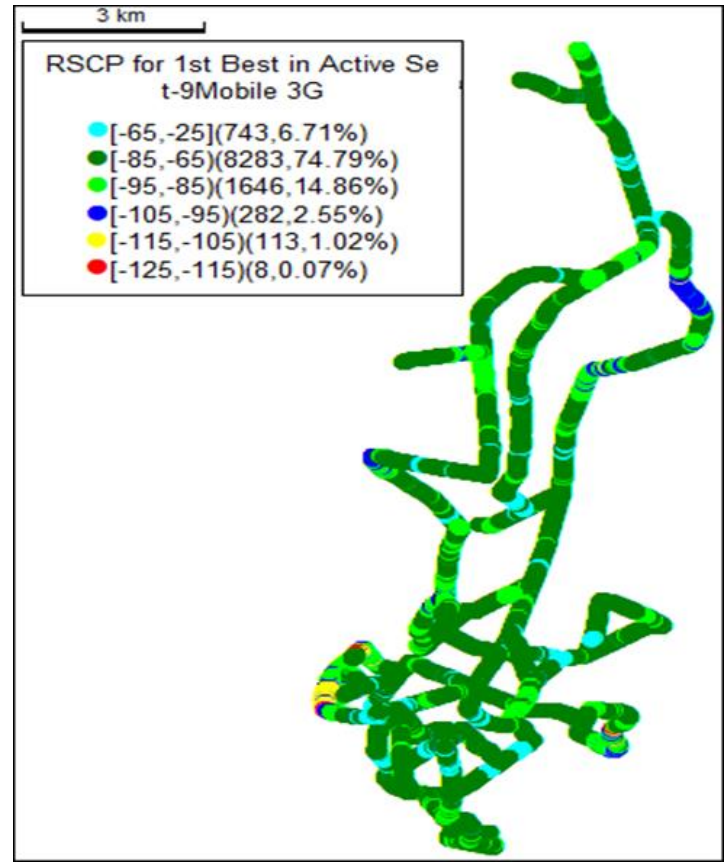

Figure 14 UMTS coverage plot for 9mobile Network

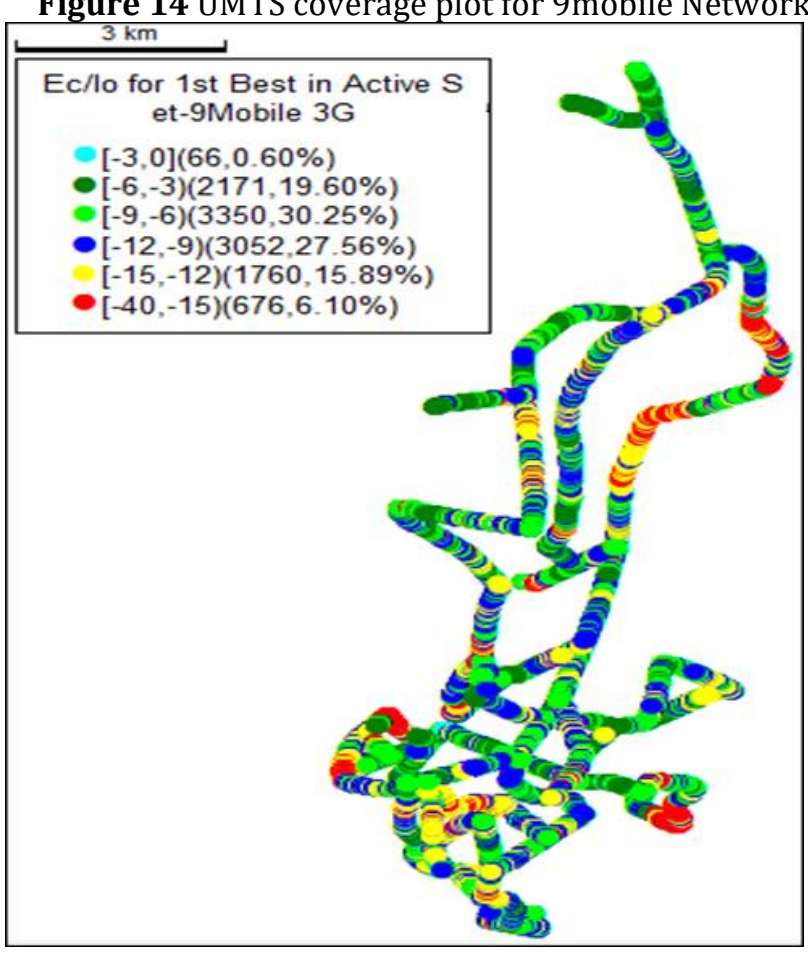

Figure 16 UMTS Quality Plot for 9mobile Network

\subsection{Overall Analysis of GSM and UMTS Technology for the four Networks}

In this section, we shall assess, in this section, the network KPIs under investigation in order of their ranking irrespective of the technology.

For CST, the UMTS technology of MTN was adjudged the best with the fastest time to connect a call at 2.211 seconds. This was followed by the UMTS technology of Airtel, GSM technology of MTN, GSM technology of Globacom, UMTS technology of 9mobile, GSM technology of Airtel, GSM technology of 9mobile and finally, the GSM technology of Globacom with CST of 3.990 seconds. It is worthy to note that during the period of study, the networks met with the NCC benchmark of at most 6 seconds for CST. 
For HOSR, the UMTS technology of MTN, UMTS technology of Airtel and UMTS technology of 9mobile came first with $100 \%$ handover. This was followed by the UMTS technology of 9mobile, GSM technology of Globacom, GSM technology of Airtel, GSM technology of 9mobile and lastly the GSM technology of MTN. All networks met with the minimum benchmark of at least 98\% except the GSM technology of MTN that fell below the benchmark with 97.13\%.

For DCR, the UMTS technology of MTN, UMTS technology of Airtel, UMTS technology of 9mobile and the GSM technology of Globacom performed superbly with $100 \%$ successfully completed calls. Other networks did not meet up with NCC benchmark of at most 1\%. The GSM technology of MTN had DCR of 1.47\%, the GSM technology of Airtel had DCR of $1.52 \%$, followed by the GSM technology of 9mobile with $3.03 \%$ and lastly the UMTS technology of Globacom with $5 \%$.

For CSSR, an outstanding performance of $100 \%$ was gotten from the UMTS technology of Airtel, the GSM technology of Airtel, the GSM technology of MTN, and the GSM technology of Globacom. Then followed by the GSM technology of MTN with $98.51 \%$ and the GSM technology of Globacom with $98.36 \%$. The UMTS technology of 9 mobile had $96.77 \%$ and the GSM technology of 9 mobile had $91.67 \%$, falling below the NCC benchmark of $98 \%$.

The best network coverage was gotten from the GSM technology of MTN, with $96.49 \%$ of the area under study having good coverage. This was judged based on the NCC recommended benchmark of at least $-85 \mathrm{dBm}$. This was followed by the UMTS technology of Airtel with $96.36 \%$, the GSM technology of Globacom with 95.45\%, the GSM technology of 9mobile with $93.68 \%$, the GSM technology of Airtel with 93.64\%, the UMTS technology of MTN with 92.1\%, the UMTS technology of Globacom with $90.93 \%$ and finally the UMTS 9 mobile having good coverage of $81.2 \%$.

The GSM technology offered better network quality while the UMTS technology offered very poor network quality. In the GSM technology, 9mobile offered the best quality with $92.18 \%$, followed by Airtel with $90.68 \%$, then Globacom with 86.93\% and finally MTN with 78.43\%. The UMTS technology had Airtel with 59.40\%, 9mobile with 50.45\%, Globacom with $31.42 \%$ and lastly UMTS technology of MTN with only $17.02 \%$.

It is necessary to note that in the coverage plots and quality plots, regions denoted with light green had excellent coverage and signal quality with remarkably satisfied subscribers. Regions with deep green had very good coverage and signal quality with very satisfied subscribers. In the blue region, subscribers were satisfied because they had good coverage and signal quality. The yellow region is characterized by dissatisfied subscribers, fair coverage and signal quality with moderate interference. Finally, the red region has poor coverage and signal quality, higher interference and very dissatisfied subscribers.

\section{Conclusion}

A performance evaluation of GSM and UMTS technology for mobile networks operating in Calabar, Nigeria, was established by using a drive test approach. Collected data was analyzed using a TEMS discovery software and further examined by judging the results obtained with the NCC minimum benchmark. Results shows that both technologies had a fluctuating QoS and we, therefore, advise the network operators to visit their mobile sites frequently for optimization of their networks.

\section{Compliance with ethical standards}

\section{Acknowledgments}

We thank the staff and students of the Department of Physics, Cross River University of Technology, Calabar, who assisted us during the drive test and in the analysis of the collected data.

\section{Disclosure of conflict of interest}

There is no conflict of interest in this work.

\section{References}

[1] Mahmud H. Cellular Mobile Technologies (1G to 5G) and Massive MIMO. International Journal of Science and Research. 2019; 8(7): 929-937.

[2] Payal, Dhruv B, and Kumar P. A Research based study on Evolution of Cellular Generations (5G). International Journal of Advanced Research in Computer and Communication Engineering. 2014; 3(7): 7522-7525. 
[3] Meraj M, Kumar S. Evolution of Mobile Wireless Technology from 0G to 5G. International Journal of Computer Science and Information Technologies. 2015; 6(3): 2545-2551.

[4] Tripathi SR, Khaparde S. Analysis and Survey on Past, Present and Future Generation in Mobile Communication. IOSR Journal of Computer Engineering, National Conference on Recent Trends in Computer Science and Information Technology (NCRTCSIT-2016). 2016; 30-36.

[5] Singh H. Evolution of G: Wireless Telephony Generations. International Journal of Multidisciplinary Research and Development. 2016; 3(2): 135-141.

[6] Kishor I, Rathore P, Samaria P. A Review on Mobile Computing Wireless Communication Technology using $0^{\text {th }}$ Generation to $7^{\text {th }}$ Generation. International Research Journal of Engineering and Technology. 2020; 7(1): 19491953.

[7] Nagakannan M, Inbaraj CJ, Kannan KM, Ramkumar S. A recent review on growth of mobile generations-case study. Proceedings of International Conference on Intelligent Computing and Sustainable System (ICICSS 2018), Tamil Nadu, India. 2018; 321-326.

[8] Popoola SI, Atayero AA, Faruk N, Badejo JA. Data on the key performance indicators for quality of service of GSM networks in Nigeria, Data in Brief. 2018; 16: 914-928.

[9] Obi E, Ekah U, Ewona I. Real-time assessment of cellular network signal strengths in Calabar. International Journal of Engineering Sciences \& Research Technology. 2021; 10(7): 47-57.

[10] Emeruwa C, Ekah UJ. Pathloss model evaluation for Long Term Evolution in Owerri. International Journal of Innovative Science and Research Technology. 2018; 3(11): 491-496.

[11] Ekah UJ, Emeruwa C. Guaging of key performance indicators for 2G mobile networks in Calabar, Nigeria. World Journal of Advanced Research and Reviews. 2021; 12(2): 157-163.

[12] Emeruwa C, Ekah UJ. Investigation of the variability of signal strength of wireless services in Umuahia, Eastern Nigeria. IOSR Journal of Applied Physics. 2018; 10(3), 11-17.

[13] Ajayi OT, Onidare SO, Ayeni AA, Adebowale QR, Yusuf SO, Ogundele A. Performance Evaluation of GSM and WCDMA Networks: A Case Study of the University of Ilorin. International Journal on Electrical Engineering and Informatics. March 2021; 13(1): 87-106. 